\title{
Gaulke, Karsten, Der Ptolemäus von Kassel. Landgraf Wilhelm IV. von Hessen-Kassel und die Astronomie
}

\section{Gérald Péoux}

\section{OpenEdition}

\section{Journals}

Édition électronique

URL : http://journals.openedition.org/ifha/1680

DOI : $10.4000 /$ ifha. 1680

ISSN : 2198-8943

Éditeur

IFRA - Institut franco-allemand (sciences historiques et sociales)

Référence électronique

Gérald Péoux, «Gaulke, Karsten, Der Ptolemäus von Kassel. Landgraf Wilhelm IV. von Hessen-Kassel und die Astronomie ", Revue de l'IFHA [En ligne], Date de recension, mis en ligne le 01 janvier 2008, consulté le 22 septembre 2020. URL : http://journals.openedition.org/ifha/1680 ; DOI : https://doi.org/10.4000/ ifha. 1680

Ce document a été généré automatiquement le 22 septembre 2020.

(C)IFHA 


\title{
Gaulke, Karsten, Der Ptolemäus von Kassel. Landgraf Wilhelm IV. von Hessen-Kassel und die Astronomie
}

\author{
Gérald Péoux
}

1 Après la parution en 1543 du De Revolutionibus orbium coelestium de Copernic, l'espace germanique est pendant la seconde moitié du XVIe s. le théâtre de profonds bouleversements intellectuels. En effet, de nombreuses discussions autour de la nouvelle cosmologie s'ensuivent et de nouveaux instruments d'observation sont conçus ou améliorés afin de percer les secrets du monde. Le livre Der Ptolemäus von Kassel propose de regarder ce paysage non pas au travers des seuls contenus savants ou philosophiques, ou de figures très célèbres comme Tycho Brahe ou encore de la seule discipline astronomique, mais en examinant les activités intellectuelles, politiques et sociales du prince Guillaume IV de Hesse (1532-1592) et de son centre d'observation de Cassel, sans doute moins connu du grand public que celui d'Uraniborg qui lui est contemporain.

2 La première partie est composée de sept chapitres, dont l'objet est de situer les enjeux et les questions savantes, théologiques ou philosophiques qui se posent à cette époque ; elle est écrite par des historiens spécialistes des sujets qu'ils traitent et se révèle une clé indispensable pour aborder et comprendre les instruments, objets tangibles du musée, décrits en seconde partie dans le catalogue.

3 C'est le français Pierre de la Ramée (1515-1572) qui, ayant fui la France ravagée par les guerres de religion, compara Guillaume IV à Ptolémée et Cassel à Alexandrie, ce qui explique le titre que les auteurs ont donné au livre. L'intérêt du prince pour l'astronomie ainsi que son implication dans ce domaine sont d'autant mieux perçus que les deux premiers articles de l'ouvrage situent la discipline dans le contexte politique, religieux et savant de l'époque. L'astronomie, bien que matière subalterne dans les universités, revêtait des aspects très pratiques qui ne manquaient pas de passionner certains lettrés. Très tôt, après avoir suivi des études classiques, le prince va s'y adonner et assez rapidement définir un programme de recherche qui contribuera à sa 
notoriété et incitera d'autres princes à solliciter ses avis sur tels phénomènes célestes. Mais les incertitudes de cette discipline poussent Guillaume IV à s'orienter vers le développement d'instruments de mesure, auxquels le troisième article est entièrement consacré. Guillaume IV parvient à réunir à sa cour des artisans célèbres comme Bürgi ou Baldewein qui ont été à l'origine des principaux instruments de Cassel et notamment des horloges planétaires qui furent construites entre 1559 et 1562. L'un des articles développe leur fabrication autour, notamment, des relations entre le landgrave et le Prince-Électeur de Saxe à qui Guillaume IV en livre un modèle en 1568. Cet objet reçu par Auguste de Saxe se révèle également un moyen pour Guillaume IV d'asseoir un statut politique comme prince protestant de l'astronomie supérieure, et traduit les nombreux échanges intellectuels entre les deux duchés, notamment dans les domaines des mathématiques, de l'arpentage, de la botanique, de l'alchimie et de l'astronomie, autant d'activités appréciées et pratiquées par le prince, comme nous le montre une autre contribution au volume.

4 On ne peut décrire le centre de Cassel sans évoquer le mathématicien Christophe Rothmann, qui entre au service du Landgrave au début des années 1580 et dont les positions cosmologiques sur la matière du Ciel qu'il reconnaît fluide et aérien et non pas éthéré comme le veut la tradition, ou sur le système du monde qu'il finit par considérer héliocentrique, contre Tycho Brahe, font l'objet d'un article très argumenté.

Enfin, la question de l'héritage est abordée dans un dernier chapitre, notamment avec les travaux de Bürgi qui assiste Kepler à Prague au moment où celui-ci produit ses célèbres lois en lui apportant une assistance technique sur les horloges ou une aide sur les calculs des tables des positions des étoiles à l'origine du logarithme.

6 L'ensemble de ces contributions met en perspective les objets du catalogue, ce qui permet au lecteur d'admirer les très belles photographies des horloges, globes, sphères armillaires et autres astrolabes et d'en comprendre plus aisément les notices explicatives.

7 Gérald Péoux (Université de Paris X - Nanterre) 